\title{
BATHYMETRIC SURVEYING IN LAKE SUPERIOR: 3D MODELING AND SONAR EQUIPMENTS COMPARING
}

\author{
E. Levin ${ }^{1}$, G. Meadows ${ }^{2}$, R. Shults ${ }^{1}$, U. Karacelebi ${ }^{1}$, H. S. Kulunk ${ }^{1}$ \\ ${ }^{1}$ Michigan Technological University, School of Technology, Townsend Drive, 1400 Houghton, 49931, USA, elevin@ mtu.edu, \\ rshults@mtu.edu,ukaracel@mtu.edu,hskulunk@mtu.edu \\ ${ }^{2}$ Michigan Technological University, Great Lakes Research Center, Townsend Drive, 1400 Houghton, 49931, USA, \\ gmeadows@mtu.edu
}

Commission II, WGII/9

KEY WORDS: bathymetric surveying, autonomous underwater vehicles, sonar, seabed, profile.

\begin{abstract}
:
This paper represents the overview of hydrographic surveying and different types of modern and traditional surveying equipment, and data acquisition using the traditional single beam sonar system and a modern fully autonomous underwater vehicle (AUV) IVER3. During the study, the data sets were collected using the vehicles of the Great Lake Research Center at Michigan Technological University. This paper presents how to process and edit the bathymetric data on SonarWiz5. Lastly, it compares the accuracy of the two different sonar systems in the different missions and creates 3D models to display and understand the elevations changes. Moreover, the 3D models were created after importing the data sets in the same coordinate system. In this study, the data sets were recorded by two different sensors in the two study locations in the Keweenaw Waterway in Michigan, U.S. between the cities of Houghton and Hancock. The first one equipment is the Lowrance HDS-7 sonar on the surveying boat, and other one is the EdgeTech 2205 sonar on the fully AUV of IVER3. One of the purposes of this study is to explore the sonar post processing programs, which are very important to interpret sonar and bathymetric data, and obtained the same coordinate system of the study areas. During the project, three main processing programs were used. The first one is UnderSee Explorer 2.6, which has been used to process the data sets of Polar SV boat. Secondly, EdgeTech Discover 4600 bathymetric software used EdgeTech 2205 sonar data sets to create bathymetric files that were used in SonarWiz5. Lastly, SonarWiz5 sonar processing software can be used to process the data sets. After the data acquisition and the data process, six profiles from the first study area and the five profiles from the second study are created to compare the data sets and elevations difference. It is shown that single beam sonar might miss some details, such as pipeline and quick elevation changes on seabed when we compare to the side scan sonar of IVER3 because the single side scan sonar can acquire better resolutions to understand the $3 \mathrm{D}$ features, such as pipelines, reliefs etc.
\end{abstract}

\section{INTRODUCTION}

Hydrographic surveying is the measurement of the depth of water bodies from the water surface and charting of the seafloor using surveying measurements and sonar for navigation maps, marine construction, offshore oil exploration and drilling, an underwater pipeline, etc. Creating a bathymetric contour map is a design of the depth of the seabed and shows lines of the same depth from the coast. People have had a certain challenge to make these kinds of maps. In land surveying, we can easily understand how accurate we can measure unlike how we cannot see how accurate we measure in the bathymetric survey. Underwater measurements are the easy part because today's sonars allow us to obtain accurate distance in water. However, the problem is that we might not know how far the survey boat is from the shoreline or a control point when the measurement equipment records the distance. Oceanographers have surveyed the seafloor and the shape of the floor by using many tools. In today's world though, we use modern equipment, such as acoustic sonars, optical systems, satellites, etc. They are much faster and more accurate than ancient methods, so this equipment allows us to obtain a better result. Hydrographic surveyors use sonar systems to measure the distance from the seafloor or ocean floor. This technique uses sound propagation to navigate and detect objects from the surface vessels and underwater vehicles. Hydrographic surveying is very significant for many countries' economies because many countries' economies depend on waterways. For instance, safe and efficient movement of goods through U.S. ports is so important to develop the economy. According to the Food and Agriculture Organization of the United Nations, more than a billion tons of goods are shipped from all over the world every year. Additionally, vacation vessels carrying nearly 10 million passengers departed U.S. ports in 2010, with the cruise line industry accounting for $\$ 17$ billion in direct spending in 2010. U.S. ports, a main part of the naval transportation system might have the challenge of rising freight movements, so creating a useful bathymetric contour map is very important to developing countries' economies (NOAA, 2012).

Due to the strategic location of Lake Superior, which is the largest of the Great Lakes of North America, it has an important role in American history. It also has been a tactical commercial waterway for people who live around the Great Lakes, so the U.S government excavated many canals and connected many towns using canal systems to transfer goods. So that, the hydrographic surveying of that canals with an appropriate equipment and software is a big challenge. Especially that task becomes hard in a case of different software and equipment diversity.

\section{RELATED WORKS}

The research of different sonar equipment is a quiet common question. The study are brought about by market of new devices and software. Each year we have a deal with new models of sonar systems and its combination with other measuring equipment e.g. GNSS, IMU, laser scanning etc. (Moisan, et.al. 2015, Shia, et.al. 2017, Seube, et.al. 2017) and refined software. Another popular direction of researches is a study of different sonar systems opportunities for applied engineering tasks and environment monitoring (Tassetti, et.al. 2015, Moisan, et.al. 2015, Wright, et.al. 2016, Kulunk, 2017). Among these tasks, a special role has underwater pipeline surveying and monitoring. That is why in 
our research we tried to compare different sonars and different software for two areas, one of which has underwater pipeline. Another feature of that area is abound of obstacles for GNSS equipment, which in turn leads to additional problems with positioning. We realize that different sonar systems namely single-beam sonar and side-scan sonar have a different nature of data capturing and data structure. In spite of that, the key feature of our research to show in which circumstances and under which conditions we can use this equipment.

\section{HYDROGRAPHIC SURVEY EQUIPMENT}

The hydrographic has various effects, and most of them are related to the atmospheric and geographical conditions. All these activities helped surveyors to obtain basic information of the geographical and geophysical features of the seabed and coast. The variation effects also give the information about the streams and tides, but this data should be processed by proper techniques and methods because it might have important influence on the observation. Also, there is a relationship with the land and the characteristics and dynamics of the seas and oceans (Emine, 2006). The variation effects are divided into four main parts:

- tidal variation and the influence of position;

- water quality and temperature;

- atmospheric effects;

- position accuracy.

These effects have to be accounted before surveying and equipment choosing.

Today's hydrographic survey equipment can accurately map a sea floor and underwater topography using many different types of equipment, such as multi beam, single beam, and side scan sonar systems with the vessels' positioning data.

Most survey vessels use multi beam and side scan sonars, which use sound waves to measure depth to find and determine underwater objects. The computer of the device accurately measures the time of sound pulses from the sea bottom to its receiver to compute the water depth. Some survey vessels also use single beam echo sounders, split beam echo sounders, lead lines, and some old fashion hydrographic survey equipment. Moreover, more and more modern depth measurement techniques are used to survey. For example, remote sensing, aerial photogrammetry, and LIDAR (LIght Detection and Ranging or Laser Imaging Detection and Ranging), which is a remote sensing technology that can define underwater objects and measure distances and water depth.

It is important to note that sonars are divided into two types, active and passive sonars. Firstly, active sonars send a pulse of sound into the water. This sound pulse hits an object and bounces off the object and returns an echo to the transducer, which receives signals to compute the power of the signal and to determine the range and orientation of the object. Generally, this sonar system can be used on submarines, AUV and Remotely Operated Vehicles (ROV). It also can be towed near the survey vessel at a fixed water depth (NOAA, 2014). Secondly, passive sonar systems are mostly used to distinguish noise from submarines, ships, and marine animals. It cannot emit its own signal so the vessels, especially military vessels, want to use passive sonars because they do not want to be found easily. Moreover, passive sonars cannot measure the range of an object without any other passive devices (NOAA, 2014).

One of the important missions is depth determination for hydrographic surveys. It needs specific knowledge of underwater acoustics, modern equipment, and sensors to achieve accuracy and meet the modern hydrographic surveying standards.

Single Beam Sonar (SBS) systems have been very useful for the bathymetric surveying (Fig. 1). These systems are less expensive than other modern sonar equipment to map study areas. However, they can obtain much less spatial resolutions when you compare other modern equipment. Single beam sonars calculate the double ways from the sonar receiver to sea floor using the acoustic signals and sound velocity in water.

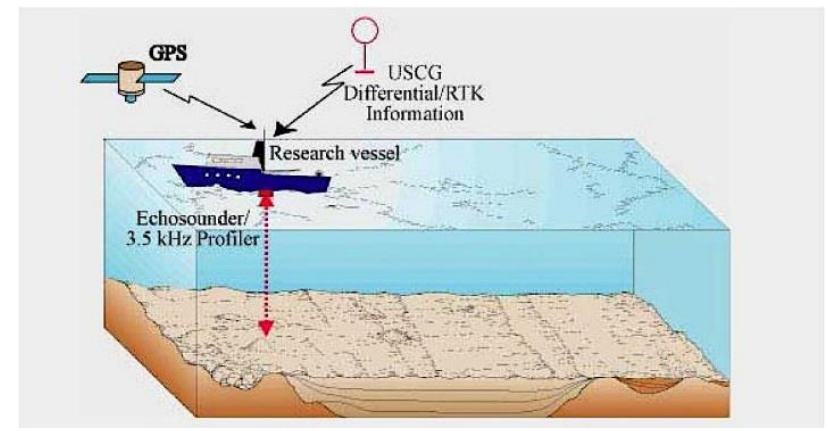

Figure 1. Single Beam Echo Sounder Principle (U.S. Geological Survey Department of the Interior/USGS,

https://woodshole.er.usgs.gov/operations/sfmapping/singlebeam .htm)

Multi beam echo sounders (MBES) is like single beam systems, and it was designed that more beams are better than single beam echo sounder. It also uses a single beam sonar way to measure the underwater surface. The sound travels in water and bounces off the underwater surface or other objects. The echo sounder can measure and record the sound traveling time to compute the depth. MBES generates so many soundings to completely cover the surveying area. This surveying coverage area depends on the depth of the surveying area. It usually covers two to four times the water depth. Moreover, MBES can produce several acoustic signals through a wide angular lateral aperture transducer, and the sound travels in water and bounce off the underwater surface or other objects. The reflection of sound echo is recorded to compute the water depth using a wide band call swath (NOAA, 2018).

Side Scan Sonar (SSS) is a special sonar system that is used to proficiently generate a large underwater image and detect the objects on the underwater surface. Some of the side scan sonars do not provide the bathymetry information. Also, this kind of sonar can be used to design a map for the bathymetric missions and surveying projects. It allows the users to understand the texture type and shape of the underwater surface. This sonar should be used together with the other sonars, such as single or multi beam sonar systems to obtain full coverage of the surveying area. Moreover, side scan sonars can be used to check the statues of the underwater pipelines and cables, bathymetric surveying, military operations and dredging applications. It is also very useful in exploring mines and petroleum underwater.

Light Detection and Ranging (LIDAR) is one of the remote sensing methods that can be used to measure the surveying places using the form of a pulsed laser and GNSS receiver. It can produce precise three dimensional information about a surveying area quickly and easily. LIDAR devices are usually placed on airplanes and helicopters to gain point clouds for traditional topographic and bathymetric maps. This system is used to establish water depths and shoreline elevations. It is important to 
say that it is related to water clarity, but it can reach depths of 50 meters (NOAA, 2013).

\section{STUDY AREAS AND DATA ACQUISITION}

\subsection{Study Locations}

The study areas are at strategic locations between the cities of Houghton and Hancock in the U.S. state of Michigan's Upper Peninsula. In 1873, Houghton and Hancock gained a significant position as a port when the Keweenaw Waterway was dredged and extended from the Portage Lake, Portage Shipping Canal and Lily in the Keweenaw Peninsula of Copper Island (Eckert, 1995).

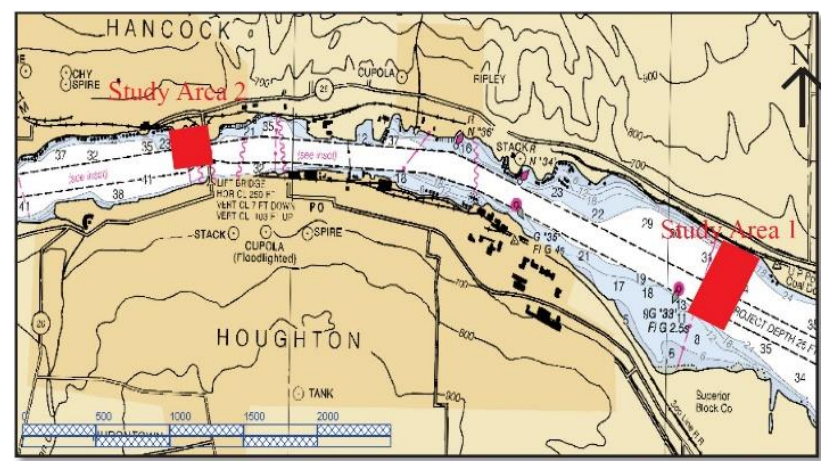

Figure 2. The study areas are in Keweenaw Waterway map in Michigan, USA including Houghton and Hancock (Base Map From: NOAA Office of Coast Survey Public Domain)

Two study locations (Fig. 2) covers areas of approximately one square $\mathrm{km}$ and depths between two and $15 \mathrm{~m}$. The first study area (Fig. 3) is on the pipeline between the cities of Hancock and Houghton in Michigan and the dimensions of the surveying area is approximately 0.9 square $\mathrm{km}(240 \mathrm{~m}$ x $340 \mathrm{~m})$.

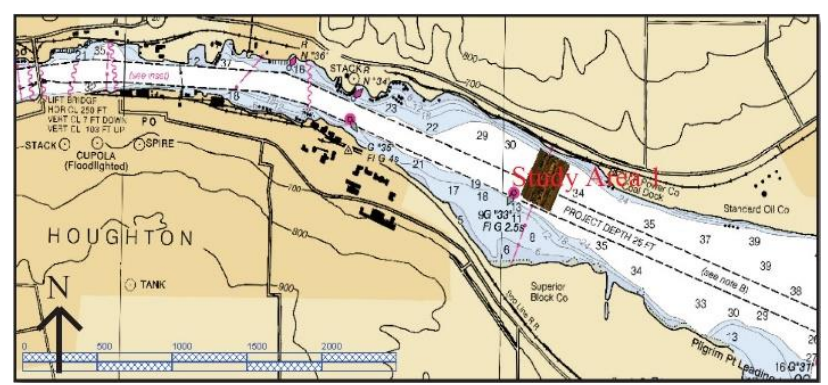

Figure 3. The Map of the First Study Area (Base Map From: NOAA Office of Coast Survey Public Domain)

The second study area is located under the Portage Lake lift bridge (Fig. 4), which is between Hancock and Houghton (Fig. 5)

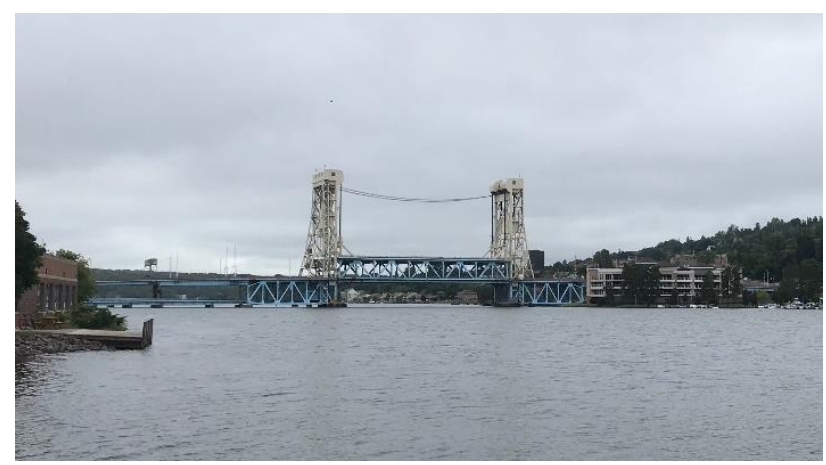

Figure 4. Hancock-Houghton Lift Bridge
That area covers the surveying area of 0.15 square $\mathrm{km}$.

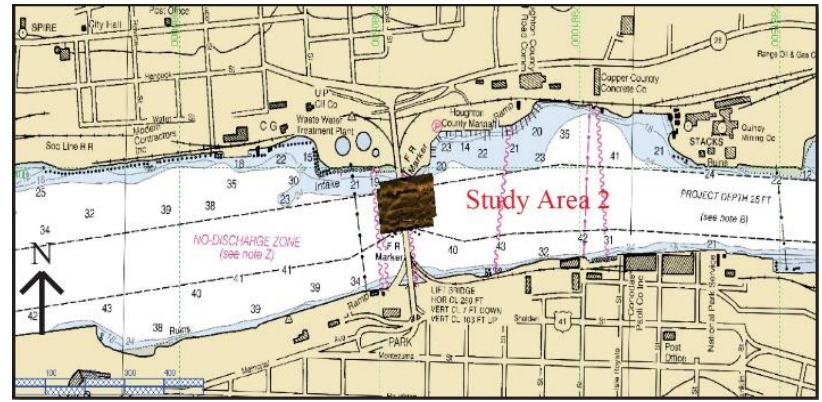

Figure 5. The Map of the Second Study Areas (Base Map From: NOAA Office of Coast Survey Public Domain)

\subsection{Data Acquisition}

The project field work was conducted by the Great lake Research Center at Michigan Technological University and the study areas were surveyed in the summer of 2015 using the ship of SV polar, which is 22 feet surveying boat and has a Lowrance HDS-7 sonar equipment, and AUV of IVER 3, which is a brand-new equipment and has a EdgeTech 2205 modern digital side scan. These two surveying vehicles surveyed two different study areas and obtained two different data sets.

\subsection{Data Processing}

The data sets were processed on two different software to convert raw surveying data, and to obtain usable information and produce bathymetric surveying to create the models. In the process steps, the raw GNSS navigations data were converted to the Michigan State Plane Coordinate System, which is Michigan North Zone 2111 and UTM Zone 16 (Sickle, 2015). There are Undersee Explorer 2.6 and SonarWiz5 sonar processing software used to process the data sets. Moreover, EdgeTech Discover 4600 bathymetric software used Edge Tech 2205 sonar data sets to create bathymetric files that were used in SonarWiz5. SV Polar vehicle surveying data were processed on UnderSee Explorer software, which uses a GNSS and sounder data to create high definition bathymetry charts. Also, this software allows the surveyors to import a sonar log file in real time with a computer. In the Fig. 6, the software is shown.

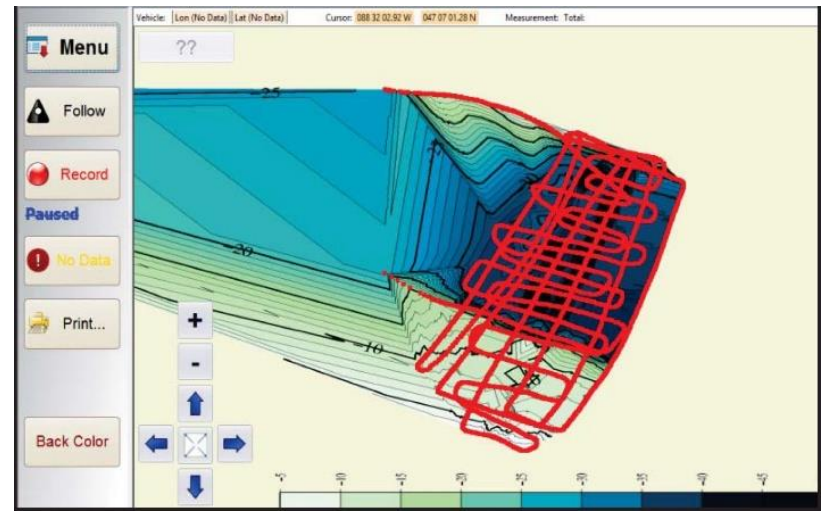

Figure 6. UnderSee Explorer Software

It is important to say that this software is designed to be easy to use. Receiving navigation positions, sounder positions and depth data are instantly recorded and quickly processed to draw a contour map on a computer screen in this real time mode and can be quickly gathered and exported to your mission critical applications. 
EdgeTech's software offers an approach to manage, accumulate, and show bathymetry and side scan sonar data. These data sets can be displayed on a color waterfall and be stored in the binary EdgeTech JSF file format (EdgeTech Software 2013).

SonarWiz5 is the data procession and real time friendly sonar data acquisition software that is designed for an all-in-one suite of programs to meet your mapping standards, minimize project cost and project time. It also helps the users to process your data quickly and minimize the amount of software you need for the surveying project. It has information about the side-scan and subsonar equipment; therefore, the users do not need to set up many complicated settings. It can be easily said that SonarWiz5 is easy to use and can produce high quality results. Also, SonarWiz5 is able to export in many different raster and vector format types, such as sonar mosaics, digitized features, depth contours, magnetometer contours, survey and others to Google Earth KML/KMZ format (SonarWiz5 Software, 2013).

In this study, SonarWiz5 was used to process the IVER3 AUV sonar data to get the bathymetric coordinates of the study areas. During the study, the bottom tracking was provided to generate better views to edit the data; it is also one of the steps to be done before the signal processing and target recognizing.

\section{STUDY RESULTS}

\subsection{Three Dimensional Views Creation}

After the data acquisition and the data process, and editing the data sets, SonarWiz5 Software was used to create the digital elevations models of the study areas using more than 350,000 observations from AUV IVER3 sensor, and to display the three dimensional surfaces using the interpolation method on SonarWiz5. Moreover, the AutoCAD software was then used to create the digital elevations models of the study areas using less than 3,000 observations from the traditional beam sonar of the Polar Boat, and to display the three dimensional surfaces on AutoCAD. In addition, the six profiles from the first study area and the five profiles from the second study were created to compare the data sets of AUV IVER3 and Polar Boat's single beam sonar. In this section, the quality of observations is in the first order of Minimum Standard for Hydrographic Surveys according the International Hydrographic Organization (IHO, 2005; IHO, 2008). However, it can be seen that the single beam sonar might miss some details because of the sensor resolutions and the way it uses. The side scan sonar can have better resolutions and more dense points, which can be used for the pipeline constructions or making a map for offshore petroleum drilling or exploring projects.

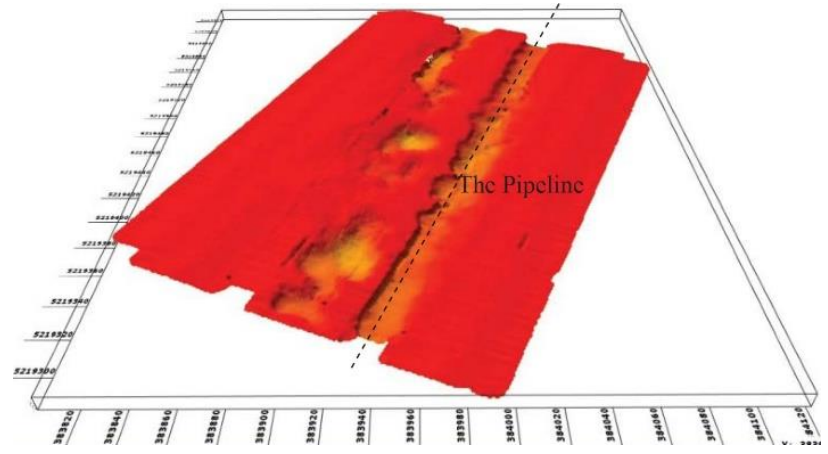

Figure 7. Three Dimensional View of the First Study (the Pipeline) Area Using the AUV IVER 3 Data on SonarWiz5

Furthermore, the two sonar sensors are compared, and explained the positions errors because of the GNSS and multipath error and missing details on the seabed because of the lack of observations or interpolations. The surface models can be seen in the figures below (Fig. 7 - Fig.10).

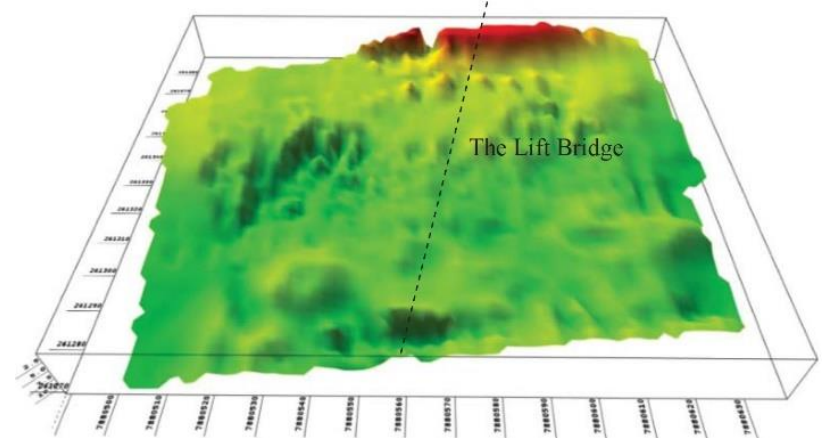

Figure 8. Three Dimensional View of the Second Study (Under the Lift Bridge) Area Using the AUV IVER3 Data on SonarWiz5

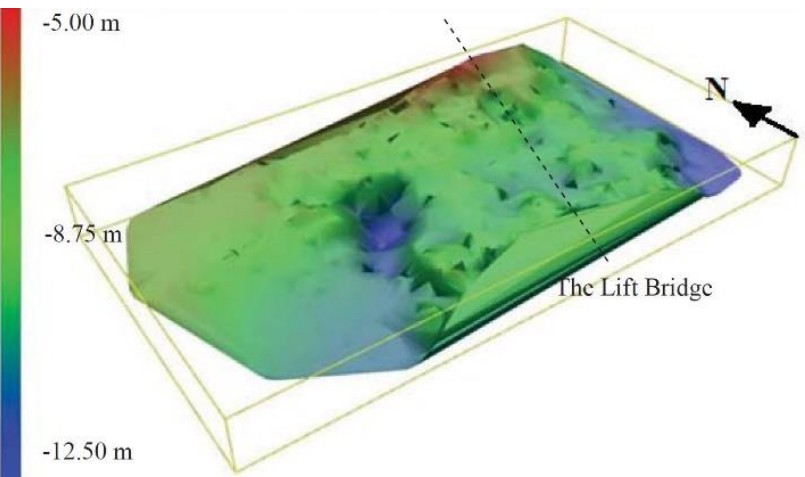

Figure 9. Three Dimensional View of the Second Study (Under the Lift Bridge) Area Using the Polar Boat Data on AutoCAD Carlson

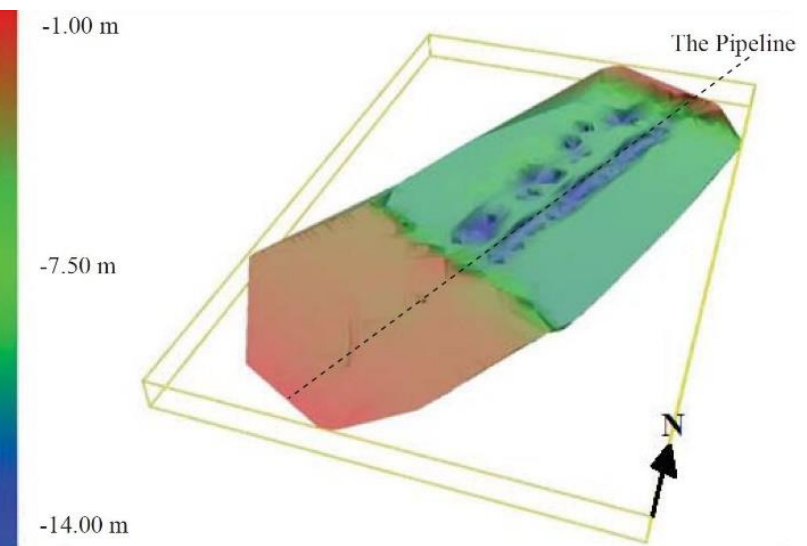

Figure 10. Three Dimensional View of the First Study (the Pipeline) Area Using the Polar Boat's Data on AutoCAD Carlson

\subsection{Compare the Data Sets}

After creating the surface models, the six profiles and five profiles are plotted to compare the difference of the observations (Fig. 11). 


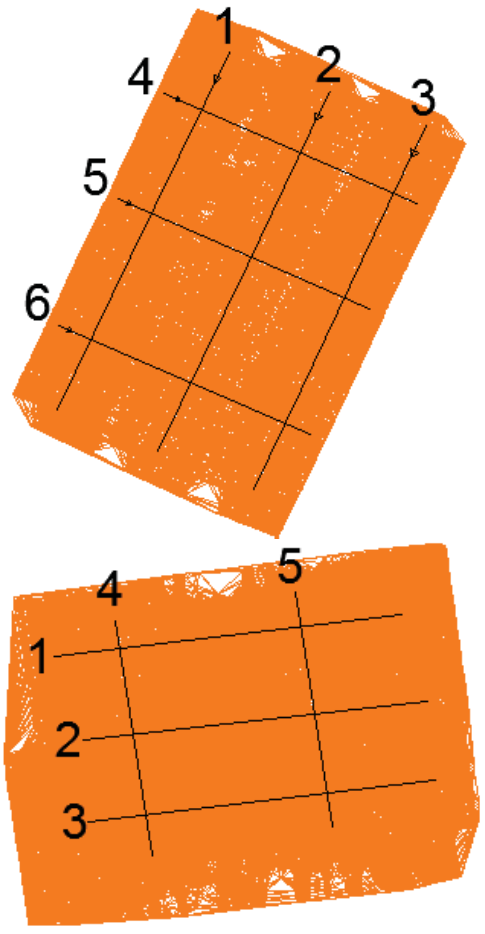

Figure 11. The First and Second Study Area's Profiles

It also shows the missing details, such as holes or small bumps on the surfaces.
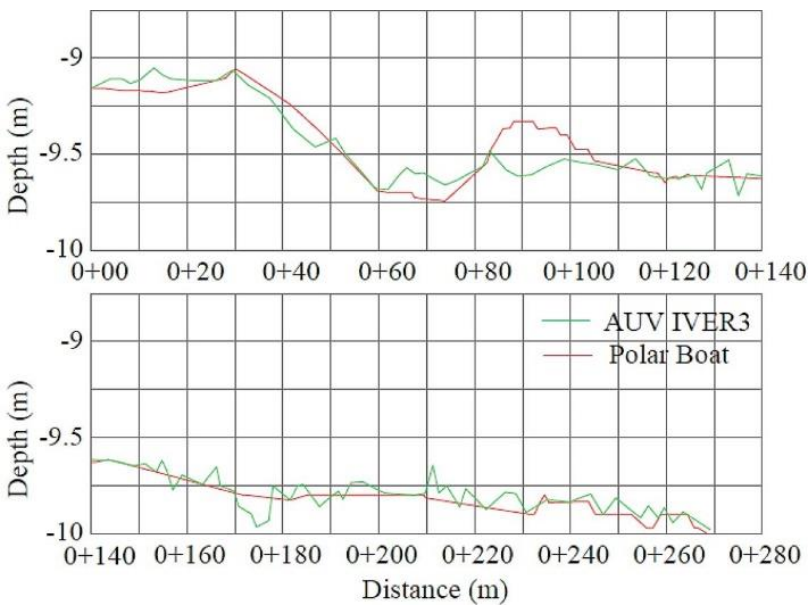

Figure 12. The First Profile of the First Study Area

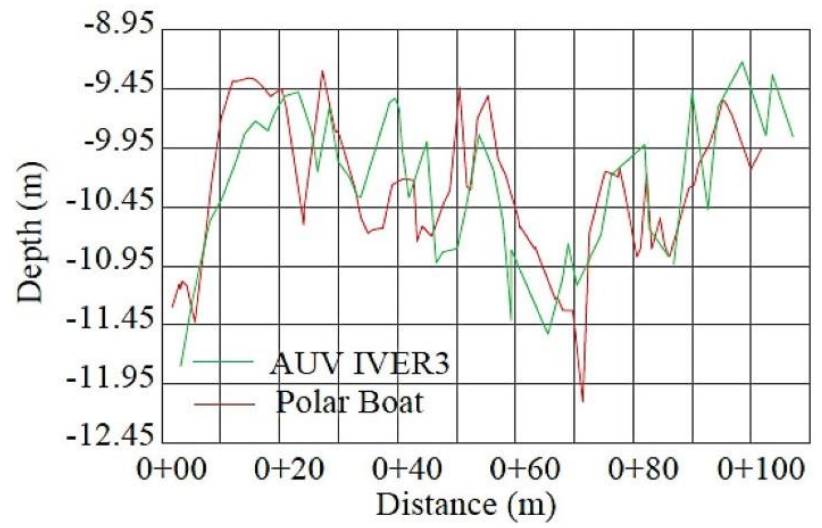

Figure 13. The Third Profile of the Second Study Area
Insofar as we do not have a precise 3D model of studied areas as e.g. in (Débese, et.al. 2012), there is only way to check and compare our data, it is profiles comparison. The some examples of profiles for two study areas can be seen in the figures (Fig. 12 and Fig. 13) below, and the value of observations and RMS errors can be seen in the table 1 .

\begin{tabular}{|c|c|}
\hline \multicolumn{2}{|c|}{ First Study Area (The Pipeline) } \\
\hline Profile's number & RMS (m) \\
\hline 1 & 0.07 \\
\hline 2 & 0.13 \\
\hline 3 & 0.10 \\
\hline 4 & 0.20 \\
\hline 5 & 0.29 \\
\hline 6 & 0.15 \\
\hline Second Study Area (The Lift Bridge) \\
\hline 1 & 0.11 \\
\hline 2 & 0.11 \\
\hline 3 & 0.21 \\
\hline 4 & 0.10 \\
\hline 5 & 0.21 \\
\hline
\end{tabular}

Table 1. The RMS Errors of the Profiles

After comparison amongst eleven profiles, it is possible to make some interesting conclusions.

\section{CONCLUSION}

In today's world, hydrographic surveying is very important for many countries' economies because several countries' economies depend on waterways, so safe and efficient movement of goods through the ports is very significant to grow economies. As a result of the economic reasons, obtaining bathymetric data and making bathymetric charts are very important. People have faced certain challenges to make these kinds of charts. This paper presents the data acquisition using the traditional sonar system and modern AUV, and processing their sonar and bathymetric data sets on different surveying software. Lastly, it also compares the accuracy of the two different sonar systems in the different missions and creates three dimensional models to display and understand the elevations changes. In this study, the data sets were recorded by two different sensors in the two study locations in the Keweenaw Waterway in Michigan, U.S. between the cities of Houghton and Hancock during the summer of 2015. The first one is the Lowrance HDS-7 sonar on the surveying boat, and other one is the EdgeTech 2205 sonar on AUV of IVER3, which have been rapidly becoming a significant vehicle in the bathymetric surveying operations.

One of the purposes of this study was to explore the sonar post processing programs, which are very important to interpret sonar and bathymetric data. During the project, three main processing programs were used. The first one is UnderSee Explorer 2.6, which has been used to process the data sets of Polar SV boat. Secondly, EdgeTech Discover 4600 bathymetric software used EdgeTech 2205 sonar data sets to create bathymetric files that were used in SonarWiz5. Lastly, SonarWiz5 sonar processing software was used to process the data sets.

It can be said that these bathymetric surveying equipment and software can be easily used in the missions,

- determining and observing shorelines, and underwater surface - offshore oil exploration, offshore oil rigs and drilling - pipeline and cable routing constrictions, 
- creating charts for multipurpose

- marine construction, maritime navigation and dredging for canals.

However, during the data acquisition, the observations had some gross errors in depth because of the survey vessel and AUV combine GNSS position with sonar equipment. One of the reason of those errors for the second study area was measurements accomplishment just under steel bridge. The bridge construction led to multipath effect on GNSS. It can explain a high level of blunders that were excluded from measurements using of threesigma rule before RMS calculation.

After the data acquisition and the data process, AutoCAD software was used to create the digital elevations models of the study areas, and to display the three dimensional surfaces. Moreover, the six profiles from the first study area and the five profiles from the second study were created to compare the data sets and elevations difference of AUV IVER3 and Polar Boat's single beam sonar. It is shown that single beam sonar might miss some details, such as pipeline and quick elevation changes on seabed when we compare to the side scan sonar of IVER3 because the single side scan sonar can acquire better resolutions to understand the three dimensional features, such as pipelines, reliefs etc. However, sometimes using single beam sonar can save your project time and money because the single beam sonar is cheaper than side scan sonars and the processing might be easier than the side scan data.

\section{ACKNOWLEDGEMENTS}

Authors would like to say thank you for the opportunity given by the Great Lake Research Center at Michigan Technological University to carry out this research.

\section{REFERENCES}

Débese, N., Seube, N., Heydel, L. 2012. Qualitative and quantitative description of multibeam echosounder systematic errors on rocky areas, Marine Geodesy, VOL. 36, 306-321, http://dx.doi.org/ 10.1080/01490419.2011.634963

Eckert, K.B., 1995. Buildings of Michigan (Society of Architectural Historians), Oxford University Press, p. 461.

EdgeTech, 2013. Discover Bathymetric Acquisition Software Manual, 1st ed: EdgeTech, 47 p.

Emine, O.G., 2006. Near Shore Bathymetric and Topographic Survey in Marmara Sea, MSc Thesis, Bogazici University, Turkey.

IHO, 2005. International Hydrographic Organization Manual on Hydrography, International Hydrographic Bureau, May 2005, 1 st ed., 46 p.

IHO, 2008. IHO Standards for Hydrographic Surveys, vol. Special Publication No. 44, 5th Edition ed. MONACO: International hydrographic Bureau, 36p.

Kulunk, H.S., 2017. Lakebed characterization using side-scan data for investigating the latest Lake Superior coastal environment conditions, MSc Thesis, Michigan Technological University, US.

Moisan, E., Charbonnier, P., Foucher, P., Grussenmeyer, P., Guillemin, S., Koehl, M., 2015. Building a 3D reference model for canal tunnel surveying using sonar and laser scanning, Int. Arch. Photogramm. Remote Sens. Spatial Inf. Sci., XL-5/W5,
153-159, https://doi.org/10.5194/isprsarchives-XL-5-W5-153$\underline{2015}$

NOAA, 2012. Hydrographic Survey Priorities, Office of Coast Survey, Available: https://nauticalcharts.noaa.gov/publications/docs/nationalhydrographic-survey-priorities/nhsp-full\%20document2012.pdf

NOAA, 2013. NOAA Technical Memorandum NOS CS 32 - A procedure for developing an acceptance test for airborne bathymetric lidar data application to NOAA charts in shallow waters, Office of Coast Survey, 52 p., Available: https://repository.library.noaa.gov/view/noaa/2645

NOAA, 2014. SONAR, Office of Coast Survey, Available: http://oceanexplorer.noaa.gov/technology/tools/sonar/sonar.htm

NOAA, 2018. Hydrographic Specifications and Deliverables, 159 p., Office of Coast Survey, Available: https://nauticalcharts.noaa.gov/publications/docs/standardsand-requirements/specs/hssd-2018.pdf

Seube, N Keyetieu, R. 2017. Multibeam echo sounders-IMU automatic boresight calibration on natural surfaces, Marine Geodesy, VOL. 40, NOS. 2-3, 172-186, http://dx.doi.org/10.1080/01490419.2017.1310156

Shia, B., Lub, X., Yanga, F., Zhang, C., Lv, Y., Cheng, M. 2017. Shipborne over- and under-water integrated mobile mapping system and its seamless integration of point clouds, Marine Geodesy, VOL. 40, NOS. 2-3, 104-122, http://dx.doi.org/10.1080/01490419.2016.1272510

Sickle, J.V., 2015. GPS for Land Surveyors, 4th ed.: CRC Press, 349 p.

SonarWiz5, 2013. SonarWiz5 User Guide, California Chesapeake Technology Inc., 791 p.

Tassetti, A. N., Malaspina, S., and Fabi, G. 2015. Using a multibeam echosounder to monitor an artificial reef, In Proc. Int. Arch. Photogramm. Remote Sens. Spatial Inf. Sci., XL-5/W5, 207-213, https://doi.org/10.5194/isprsarchives-XL-5-W5-207$\underline{2015}$

Wright, R.G., Baldauf, M. 2016. Hydrographic Survey in remote regions: using vessels opportunity equipped with 3-dimensional forward-looking sonar, Marine Geodesy, VOL. 36, 306-321, http://dx.doi.org/10.1080/01490419.2011.634963 